\title{
1 Ultra-Slow Throw Rates of Polygonal Fault Systems
}

2 James J. King ${ }^{1}$, Joe A. Cartwright ${ }^{1}$

$3{ }^{1}$ Department of Earth Sciences, University of Oxford, Oxford OXI 3AN, UK

4

5 ABSTRACT

6 Polygonal Fault Systems (PFS) are an enigmatic class of small non-tectonic extensional faults.

$7 \quad$ PFS are predominantly hosted in fine-grained sedimentary tiers and are prevalent along many

8 continental margin basins. The genesis of PFS is widely debated and little is known about the

9 timeframe for polygonal fault growth. We present the first measurements of throw rates for

10 polygonal faults by measuring the vertical offset of seven age-calibrated horizons mapped using

11 three-dimensional seismic reflection data from the Norwegian Sea. Individual polygonal faults

12 exhibit a range of throw rate profiles through time, ranging from near linear to singly or multiply

13 stepped. The stepped profiles have a range of short-term throw rates ranging from 0 to $18 \mathrm{~m} / \mathrm{Ma}$.

14 Time-averaged throw rates of 180 polygonal faults over the entire 2.61-0 Ma interval are

15 normally distributed and range between 1.4-10.9 m/Ma. We convert our PFS throw rates to

16 displacement rates and compare these to published displacement rates for gravity driven and

17 tectonic normal faults. We find that the displacement rates of polygonal faults mark the lower

18 limit of a continuous spectrum of extensional fault displacement rates; they are up to two orders-

19 of-magnitude slower than gravity-driven faults, and up to three orders-of-magnitude slower than

20 the fastest growing tectonic faults. We attribute the ultra-slow kinematic behaviour to the non-

21 tectonic nature of polygonal faults where throw accumulates primarily through dewatering of the

22 largely fine-grained sediments comprising the host layers for the PFS, and differential volumetric

23 strain between the fault footwalls and hangingwalls. 


\section{INTRODUCTION}

26 First identified as intra-formational faults within Eocene and Oligocene claystones of Belgium

27 over 30 years ago (Henriet et al., 1988), polygonal faults are now recognised in over 160 basins

28

29

30

31

32 worldwide, where they often extend over vast areas $\sim 10^{5}-10^{7} \mathrm{~km}^{2}$ (Cartwright et al., 2003;

Cartwright, 2011). Polygonal Fault Systems (PFS) have attracted considerable attention in recent years partly because of their ubiquity in many fine-grained slope depositional systems, but also because of their importance as sealing sequences for petroleum, $\mathrm{CO}_{2}$, and high grade nuclear waste (Cartwright, 2011). Polygonal faults can also be used to guide the search for deep-water clastic reservoirs (Jackson et al., 2014; Turrini et al., 2017). More fundamentally, PFS are interesting as structures because they are a challenge for classical soil mechanical theory in that they form during early burial, under conditions of net zero lateral strain, yet represent shear failure of unconsolidated granular materials (Shin et al., 2010).

\section{The structural characteristics of PFS are well documented (see Cartwright, 2011 and references} therein). PFS are developed in 'tiers', as laterally extensive arrays of layer-bound non-tectonic normal faults. These arrays are typically characterised by multi-directional fault patterns in planform, hence the name 'polygonal fault systems'. Throw profiles on individual polygonal faults are relatively well documented from a number of different PFS and exhibit similar variations to those seen on many small tectonic normal faults, albeit with modified forms due to the complex three-dimensional intersection geometries resulting from the polygonal architecture (Nicol et al., 2003; Stuevold et al., 2003; Neagu et al., 2010; Wrona et al., 2017). An empirical scaling relationship has been suggested for PFS between the maximum throw and the height of a 
47 polygonal fault, where maximum throw values are around 3-6\% of the fault height (Shin et al., 48 2010).

50 Although the processes that govern the nucleation and propagation of polygonal faults are 51 generally considered to be unrelated to far-field tectonic stresses (Goulty, 2008; Cartwright et al., 52 2003; Verschuren, 2019), there is as yet no agreement on their precise genetic evolution.

53 Suggested mechanisms include gravity sliding, density inversion, overpressure, gravitational 54 loading, and diagenetically-induced shear failure (Cartwright et al., 2003; Goulty, 2008;

55 Cartwright, 2011; Verschuren, 2019). Advances in our understanding of PFS have been hindered 56 in part by a scarcity of field outcrop examples to provide sub-seismic observations of the fault 57 zones and associated minor structures (Tewksbury et al., 2014; Verschuren, 2019). An 58 additional, important unconstrained parameter to date has been the lack of any direct 59 measurements of throw rates of polygonal faults.

60

61 Here we attempt to bridge this gap in knowledge by presenting the first direct measurements of 62 throw rates for polygonal faults, using an exceptional seismic reflection and well data set from 63 the Norwegian Sea. The key to measuring the throw rates is, firstly, identifying currently active 64 faults, secondly, establishing that they propagated to the seabed at an earlier stage in their 65 evolution, and thirdly, having good age calibration of horizons that are offset by the faults. These 66 criteria are fulfilled by the combination of high-resolution 3D seismic reflection and borehole 67 data collected by the Ocean Drilling Project (ODP). Our results may not be fully representative 68 of the entire spectrum of PFS so far identified globally, but they at least provide direct 69 constraints for those attempting to model the evolution of these extraordinary structures. 
71 GEOLOGICAL SETTING

72 The study area is located within the Vøring Basin on the outer part of the Norwegian continental

73 margin (Fig. 1A), and extends over a small area of a laterally extensive PFS tier developed

74 within Eocene to Pliocene hemipelagic sediments (Gay \& Berndt, 2007; Ireland et al., 2010;

75 Neagu et al., 2010). Previous studies of this PFS in nearby areas have described the detailed

76 geometry of the system and its relationship to the stratigraphy (Hansen et al., 2005; Gay \&

77 Berndt, 2007; Ireland et al., 2010; Neagu et al., 2010). The PFS tier is almost uniform in

78 thickness $(\sim 1000 \mathrm{~m})$ across the study area (Fig. 1B), but varies in thickness over the rest of the

79 basin. Host strata comprise fine-grained siliceous mudstones and claystones of the Naust, Kai,

80 and Brygge formations, with a prominent Opal A/CT diagenetic phase boundary occurring in the

81 lower third of the tier (Fig. 1B \& 1C) (Ireland et al., 2010; Neagu et al., 2010).

82

83 METHODS

84 We mapped the faults and horizons in the study area using two adjoining high-resolution 3D

85 seismic reflection surveys (Fig. 1A). These surveys (SH0701 and BG0904), have a bin spacing

86 of $6.25 \mathrm{~m}$ and $25 \mathrm{~m}$, respectively, and a vertical resolution of $\sim 6 \mathrm{~m}$ and $\sim 10 \mathrm{~m}$ respectively in the

87 uppermost sedimentary interval (see GSA Data Repository, Fig. DR1). We plotted detailed

88 throw profiles for 52 individual polygonal faults by measuring the vertical offset for up to 70

89 horizons in two way travel time (TWT) (Fig. DR3). We transform the throw versus TWT plots

90 into throw versus geologic age plots using seven bio- and magnetostratigraphic dated marker

91 horizons distributed throughout the 0-2.61 Ma interval, which is the focus of the study. We

92 convert dated marker horizons and formation boundaries from two wells, ODP 644 and 6604/2- 
93 1, to milliseconds TWT from depth in meters, using an internal velocity of $1600 \mathrm{~m} / \mathrm{s}$ (Eldholm et

94 al., 1987). The uncertainty in the depth conversion of the dated marker horizons on the seismic

95 reflection data equates to $+/-0.1$ Ma for horizons $<1$ Ma and $+/-0.2$ Ma for horizons $>1 \mathrm{Ma}$ (for

96 detailed description see GSA Data Repository). Throw measurements of the age-calibrated

97 horizons are considered accurate to $+/-1 \mathrm{~m}$ (c.f. Townsend et al., 1998). Time-averaged throw

98 rates are derived from the 2.61 Ma horizon to the present day seabed, by dividing the throw by

99 the elapsed time.

100

101 RESULTS

102 The base of the PFS tier is identified as the base of the Brygge Formation (Eocene-Oligocene)

103 (Fig. 1B), and $>90 \%$ of the basal fault tips occur at this horizon. In contrast, there is an upward

104 reduction in fault density and the polygonal fault upper tips terminate at a range of seismic

105 reflections. Only the larger throw faults continue upwards to tip out at or close to the modern

106 seabed (Fig. 1B, 2A, 2B). These polygonal faults have measureable bathymetric expression (Fig.

107 2A) suggesting continued activity to the present day (c.f. Berndt et al., 2012).

108

109 On a small number of the larger faults, reflection-bound intervals thicken noticeably across the

110 faults in a manner typical of localised syn-sedimentary growth (Cartwright et al., 1998; Childs et

111 al., 2003) (Fig. 2C \& 2D). These 'growth packages' are comparable to those identified elsewhere

112 associated with polygonal faults (e.g. Stuevold et al., 2003; Wrona et al., 2017). They are not

113 found at any specific horizon, but are sporadically distributed throughout the interval

114 corresponding to the last 2.61 Myrs. Average sedimentation rates outpace displacement rates by 
115 at least one order of magnitude during this interval (GSA Data Repository Fig. DR5). This may explain why growth packages are so infrequently developed in the study area.

118 We constructed throw versus depth plots for 52 widely distributed polygonal faults whose upper 119 tips are at or close to the present day seabed. These plots (GSA Data Repository Fig. DR3) show 120 that throw increases downwards from the seabed to a maximum value in the central to lower 121 third of the tier, and then decreases downwards to the basal tips, in a similar manner to that 122 previously described for polygonal faults (e.g. Neagu et al., 2010). The upper portions of these 123 plots are transformed into throw versus geological age profiles (Fig. 3A), whose gradient 124 changes reveal temporal changes in throw rate (Fig. 3A, DR4).

125

126 Individual faults exhibit a range of profiles of throw with time, from almost linear profiles 127 (constant throw rate with time, e.g. Fig. 3A, PF_037) to singly or multiply stepped (variable 128 throw rate through time with zero gradient stasis intervals, e.g. Fig 3A, PF_029). Of the 52 129 faults, around $60 \%$ of profiles are approximately linear, or smoothly varying, and the remainder 130 are stepped (Fig. 3A). The stepped profiles exhibit a range of short-term throw rates ranging 131 from 0 to $18 \mathrm{~m} / \mathrm{Ma}$.

133 In addition to the detailed throw versus age profiles, we derive time-averaged throw rates from a 134 larger sample of 180 individual faults for the entire 2.61-0 Ma interval (Fig. 3B). The measured 135 throw rates are normally distributed and range between 1.4-10.9 m/Ma, with a mean and median 136 of $5.7 \mathrm{~m} / \mathrm{Ma}$ and $5.6 \mathrm{~m} / \mathrm{Ma}$ respectively. 


\section{DISCUSSION}

139 In order to measure throw rates for faults from upper tip geometries of the type presented above,

140 it must be clear that the upper tips propagated in a syn-sedimentary fashion, i.e. with the tip at or

141 close to the sediment-water interface (Childs et al., 2003; Baudon \& Cartwright, 2008). The

142 throw rate data presented here all come from polygonal faults with upper tips at or within a few

143 metres of the current seabed. The occurrence of small 'growth packages' within the age-

144 calibrated stratigraphy (Fig. 2C, 2D), albeit infrequent, and the presence of polygonal faults at or

145 within a few meters of the modern seabed (Fig. 1B, 2A, 2B) indicates that the upper tips of the

146 PFS have intersected the paleo-seabed throughout our chronostratigraphic study interval, and

147 propagated upwards with sedimentation in an active syn-sedimentary fashion. This interpretation

148 is consistent with that of Neagu et al., (2010), who dated fault activity on this PFS in relation to

149 the fossilisation of the Opal A to Opal CT diagenetic boundary. Neagu et al., (2010) used

150 measured throw values of the Opal A/CT to argue for a post-fossilisation syn-sedimentary

151 growth phase for the PFS in the Norwegian Sea. They dated the fossilisation as Late Miocene to

152 Early Pliocene, which accords well with the oldest dated horizon in our study (2.61 Ma).

153 Furthermore, we interpret stasis intervals across different polygonal fault throw profiles (Fig.

154 3A) as short periods of growth inactivity, rather than the mechanical response to blind fault

155 propagation through competent stratigraphy, because of the their non-systematic occurrence

156 relative to stratigraphic layering. It is possible that the PFS may have nucleated and propagated

157 as an array of blind faults that became syn-sedimentary later in the evolution of the system (c.f.

158 Baudon \& Cartwright, 2008). Whilst we cannot rule out the possibility that some polygonal

159 faults may have propagated to their current position as blind faults we consider it is unlikely that 160 the polygonal faults analysed in our study were blind faults over the last 2.61 Myrs. 
162 The measured throw rates both for short time increments and for the entire 2.61 Myr period of

163 the measured interval give comparable ranges in values, from 0 to $18 \mathrm{~m} / \mathrm{Ma}$ (Fig. 3B, DR4). To

164 make a comparison with previously measured fault displacement rates, we can convert our throw

165 rates to displacement rates if we assume that displacement vectors are dip-slip, and by knowing

166 the true dip of the fault planes. This correction factor amounts to 1.1 to 1.4 for faults dipping

167 between $45-70^{\circ}$. Displacement rates for these polygonal faults compared to basement detached,

168 gravity-driven, and tectonic faults from various rift settings shows that polygonal faults slip one

169 to three orders of magnitude more slowly (time averaged) than their tectonic counterparts (Fig.

170 4). Our derived PFS displacement rates are the lowest ever measured for a fault array of any type

171 globally. This comparison prompts interesting questions as to the slip mechanism: do polygonal

172 faults creep or do they exhibit stick-slip behaviour as has been suggested (Tewksbury et al.,

173 2014)?

174

175 Regardless of the underlying genetic mechanism, the accommodation of multi-directional

176 extensional faults under net-zero lateral strain conditions requires a bulk volumetric reduction of

177 the host tier. It is beyond the scope of the current study to attempt to explain the very slow

178 slipping behaviour of polygonal faults. However, the ultra-slow nature of polygonal faults is not

179 a complete surprise given the slow rates of geological processes that govern volumetric

180 reductions in shallowly buried fine-grained sediments. These slow geological processes may

181 include the rate of gravitational loading through sedimentation in deep-marine pelagic

182 depositional environments, the rate of dewatering in low-permeability fine-grained sediments,

183 and the rate of low temperature diagenetic reactions (Goulty, 2008; Cartwright, 2011). The 
184 negative throw gradients observed on the lower portions of t-z plots of all polygonal faults

185 measured to date strongly argues that there is a differential volumetric strain from footwall

186 relative to hangingwall that accounts for a large part, if not all, of the displacement that

187 accumulates along the fault throughout its growth history. We suggest that the ultra-slow rates

188 presented in this study, point to a direct link between the displacement rate and the differential

189 volumetric contractional strain rate between the footwall and hangingwall. This differential is in 190 turn likely to be governed by bulk material properties such as stiffness, Poisson's ratio, and

191 frictional coefficients (Shin et al., 2010; Roberts et al., 2014).

192

193 In isolation, the ultra-slow displacement rates do not explicitly favour one PFS genetic or growth 194 mechanism over another. They do however, offer an initial temporal benchmark that may assist 195 future computational modelling work to establish the physical property conditions and 196 mechanical evolution building on some pioneering attempts to model growth of polygonal faults 197 using finite element methods (Roberts et al., 2014).

\section{CONCLUSIONS}

200 1. We record the first throw rates for a polygonal fault system, from the Vøring Basin in the Norwegian Sea.

2. Our results from 180 polygonal faults show that time-averaged throw rates over the last 2.61 Myrs are normally distributed and range between 1.4-10.9 m/Ma. extensional fault displacement rates, where the displacement rates of polygonal faults are up to three orders of magnitude slower than the fastest-growing tectonic faults. 
4. The ultra-slow PFS throw rates are consistent with slow geological processes that drive differential bulk volumetric reductions between fault footwalls and hangingwalls.

\section{ACKNOWLEDGEMENTS}

NERC (NE/M00578X/1) and the Oxford-Radcliffe Scholarship are thanked for funding. We thank Schlumberger for providing a Petrel license. Seismic data was provided by Norske Shell A/S. We thank B. Tewksbury, C. Jackson, and S. Sonnenberg for insightful reviews, and M. Foschi, D. James, C. Kirkham, and B. Levell for helpful discussion.

\section{REFERENCES CITED}

Baudon, C., \& Cartwright, J. (2008). Early stage evolution of growth faults: 3D seismic insights from the Levant Basin, Eastern Mediterranean. Journal of Structural Geology, 30(7), 888898. doi.org/10.1016/j.jsg.2008.02.019

Berndt, C., Jacobs, C., Evans, A., Gay, A., Elliott, G., Long, D., \& Hitchen, K. (2012). Kilometre-scale polygonal seabed depressions in the Hatton Basin, NE Atlantic Ocean: Constraints on the origin of polygonal faulting. Marine Geology, 332, 126-133. doi.org/10.1016/j.margeo.2012.09.013

Cartwright, J., Bouroullec, R., James, D., \& Johnson, H. (1998). Polycyclic motion history of some Gulf Coast growth faults from high-resolution displacement analysis. Geology, 26(9), 819-822. doi.org/10.1130/0091-7613(1998)026<0819:PMHOSG>2.3.CO;2

Cartwright, J., James, D., \& Bolton, A. (2003). The genesis of polygonal fault systems: a review. Geological Society, London, Special Publications, 216(1), 223-243. doi.org/10.1144/GSL.SP.2003.216.01.15 
Cartwright, J. (2011). Diagenetically induced shear failure of fine-grained sediments and the development of polygonal fault systems. Marine and Petroleum Geology. doi.org/10.1016/j.marpetgeo.2011.06.004.

Childs, C., Nicol, A., Walsh, J. J., \& Watterson, J. (2003). The growth and propagation of synsedimentary faults. Journal of Structural geology, 25(4), 633-648. doi.org/10.1016/S0191-8141(02)00054-8

Dutton, D. M., \& Trudgill, B. D. (2009). Four-dimensional analysis of the Sembo relay system, offshore Angola: Implications for fault growth in salt-detached settings. AAPG Bulletin, 93(6), 763-794. doi.org/10.1306/02230908094.

Eldholm, O., Thiede, J., Taylor, E. (1987). Site 644: Norwegian Sea. In Proceedings of the Ocean Drilling Program, 104 Initial Reports. Ocean Drilling Program. doi.org/10.2973/odp.proc.ir.104.105.1987.

Gay, A., \& Berndt, C. (2007). Cessation/reactivation of polygonal faulting and effects on fluid flow in the Vøring Basin, Norwegian Margin. Journal of the Geological Society, 164(1), 129-141. doi.org/10.1144/0016-76492005-178

Goulty, N. R. (2008). Geomechanics of polygonal fault systems: a review. Petroleum Geoscience, 14(4), 389-397. doi.org/10.1144/1354-079308-781

Hansen, J. P. V., Cartwright, J. A., Huuse, M., \& Clausen, O. R. (2005). 3D seismic expression of fluid migration and mud remobilization on the Gjallar Ridge, offshore midNorway. Basin Research, 17(1), 123-139. doi.org/10.1111/j.1365-2117.2005.00257.x

Henriet, J. P., De Batist, M., Van Vaerenbergh, W., \& Verschuren, M. (1988). Seismic facies and clay tectonic features of the Ypresian clay in the southern North Sea. Bulletin van de Belgische Vereniging voor Geologie, 97, 457-472. 
253 Ireland, M. T., Goulty, N. R., \& Davies, R. J. (2010). Influence of pore water chemistry on silica 254 diagenesis: evidence from the interaction of diagenetic reaction zones with polygonal fault systems. Journal of the Geological Society, 167(2), 273-279. doi.org/10.1144/001676492009-049.

257

258

259

260

261

262

263

264

265

266

267

268

269

270

271

272

273

274

Jackson, C. A. L., Carruthers, D. T., Mahlo, S. N., \& Briggs, O. (2014). Can polygonal faults help locate deep-water reservoirs?. AAPG Bulletin, 98(9), 1717-1738. doi.org/10.1306/03131413104

Jackson, C. A. L. (2018). Throw Rate Variability on Gravity-Driven Normal Faults; Constraints from the Gudrun Fault, South Viking Graben, Offshore Norway. doi.org/10.1306/13652189M1153254.

Mouslopoulou, V., Walsh, J. J., \& Nicol, A. (2009). Fault displacement rates on a range of timescales. Earth and Planetary Science Letters, 278(3-4), 186-197. doi.org/10.1016/j.eps1.2008.11.031.

Neagu, R. C., Cartwright, J., \& Davies, R. (2010). Measurement of diagenetic compaction strain from quantitative analysis of fault plane dip. Journal of Structural Geology, 32(5), 641-655. doi.org/10.1016/j.jsg.2010.03.010.

Nicol, A., Walsh, J. J., Watterson, J., \& Underhill, J. R. (1997). Displacement rates of normal faults. Nature, 390, 157-159. doi.org/10.1038/36548.

Nicol, A., Walsh, J. J., Watterson, J., Nell, P. A. R., \& Bretan, P. (2003). The geometry, growth and linkage of faults within a polygonal fault system from South Australia. Geological Society, London, Special Publications, 216(1), 245-261. doi.org/10.1144/GSL.SP.2003.216.01.16 
275 Pochat, S., Castelltort, S., Choblet, G., \& Van Den Driessche, J. (2009). High-resolution record

276

277

278

279

280

281

282

283

284

285

286

287

288

289

290

291

292

293

294

295

296

of tectonic and sedimentary processes in growth strata. Marine and Petroleum Geology, 26(8), 1350-1364. doi.org/10.1016/j.marpetgeo.2009.06.001.

Roberts, D. T., Crook, A. J. L., Cartwright, J. A., Profit, M. L., \& Rance, J. M. (2014, August). The evolution of polygonal fault systems: Insights from geomechanical forward modeling. In 48th US Rock Mechanics/Geomechanics Symposium. American Rock Mechanics Association.

Shin, H., Santamarina, J. C., \& Cartwright, J. A. (2010). Displacement field in contraction-driven faults. Journal of Geophysical Research: Solid Earth, 115(7), 1-13. doi.org/10.1029/2009JB006572.

Stuevold, L. M., Faerseth, R. B., Arnesen, L., Cartwright, J., \& Möller, N. (2003). Polygonal faults in the Ormen Lange field, Møre basin, offshore mid Norway. Geological Society, London, Special Publications, 216(1), 263-281. doi.org/10.1144/GSL.SP.2003.216.01.17

Tewksbury, B. J., Hogan, J. P., Kattenhorn, S. A., Mehrtens, C. J., \& Tarabees, E. A. (2014). Polygonal faults in chalk: Insights from extensive exposures of the Khoman Formation, Western Desert, Egypt. Geology, 42(6), 479-482. doi.org/10.1130/G35362.1

Townsend, C., Firth, I. R., Westerman, R., Kirkevollen, L., Hårde, M., \& Andersen, T. (1998). Small seismic-scale fault identification and mapping. Geological Society, London, Special Publications, 147(1), 1-25. doi.org/10.1144/GSL.SP.1998.147.01.02

Turrini, L., Jackson, C. A., \& Thompson, P. (2017). Seal rock deformation by polygonal faulting, offshore Uruguay. Marine and Petroleum Geology, 86, 892-907. doi.org/10.1016/j.marpetgeo.2017.06.038 
297 Verschuren, M. (2019). Outcrop evidence of polygonal faulting in Ypresian marine clays 298 (Southern North Sea Basin) leads to a new synthesis. Marine Geology, 413, 85-98. doi.org/10.1016/j.margeo.2019.04.002

300

301

Wrona, T., Magee, C., Jackson, C. A., Huuse, M., \& Taylor, K. G. (2017). Kinematics of polygonal fault systems: observations from the northern North Sea. Frontiers in Earth Science, 5, 101. doi.org/10.3389/feart.2017.00101

Figure 1: (A) Map of the study area located in the Vøring Basin of the Norwegian Sea, that includes two 3D seismic reflection volumes, SH0701 and BG0904, that are litho- and chronostratigraphically calibrated by two industry wells and ODP 644. (B) A seismic profile of the PFS tier through ODP 644 and 6604/2-1 showing the dated horizons (from Eldholm et al., 1987) used in our analysis, alongside the stratigraphic formation boundaries, and the diagenetic Opal A/CT phase boundary. (C) Stratigraphic column of the PFS host sediments.

Figure 2: (A) Seabed variance map showing the bathymetric expression of polygonal faults. (B) Seismic cross-section showing the bathymetric expression of polygonal fault upper tips (vertical exaggeration $\sim$ x15). Faults tips are labelled FT. (C \& D) Syn-sedimentary growth package within the age-calibrated stratigraphy. 
319 Figure 3: (A) Polygonal fault throw versus horizon age for 14 polygonal fault upper tips. (B)

320 Probability density function of time-averaged PFS throw rates derived from the 2.61 Ma horizon

321 for 180 faults.

322

323

324 Figure 4: Log plot of displacement rates from extensional tectonic, gravity-driven, and 325 polygonal fault systems from basins around the world. Tectonic and gravity-driven fault 326 displacement rates sourced from; Nicol et al., (1997); Mouslopoulou et al., (2009); Dutton \&

327 Trudgill (2009); Pochat et al., (2009); Jackson (2018). PFS time-averaged throw rates are 328 converted to displacement rates using a conversion factor of 1.4. 


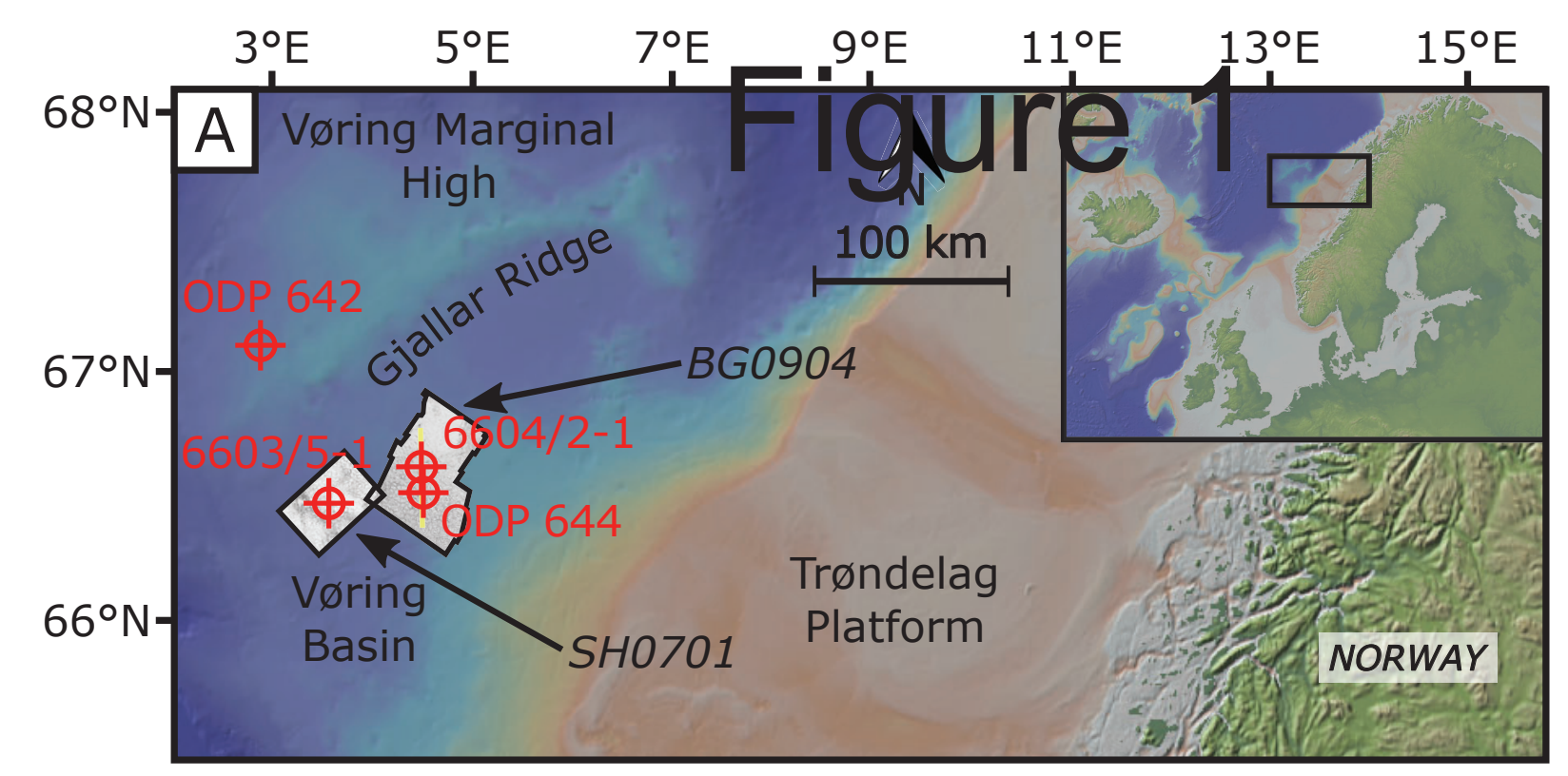

Strat Column Legend 二二二 Claystone

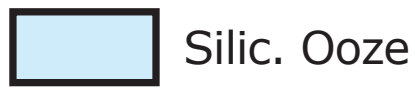

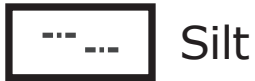

${ }_{8} \&$ Foraminifera

口ם Pyrite

* * Glauconite

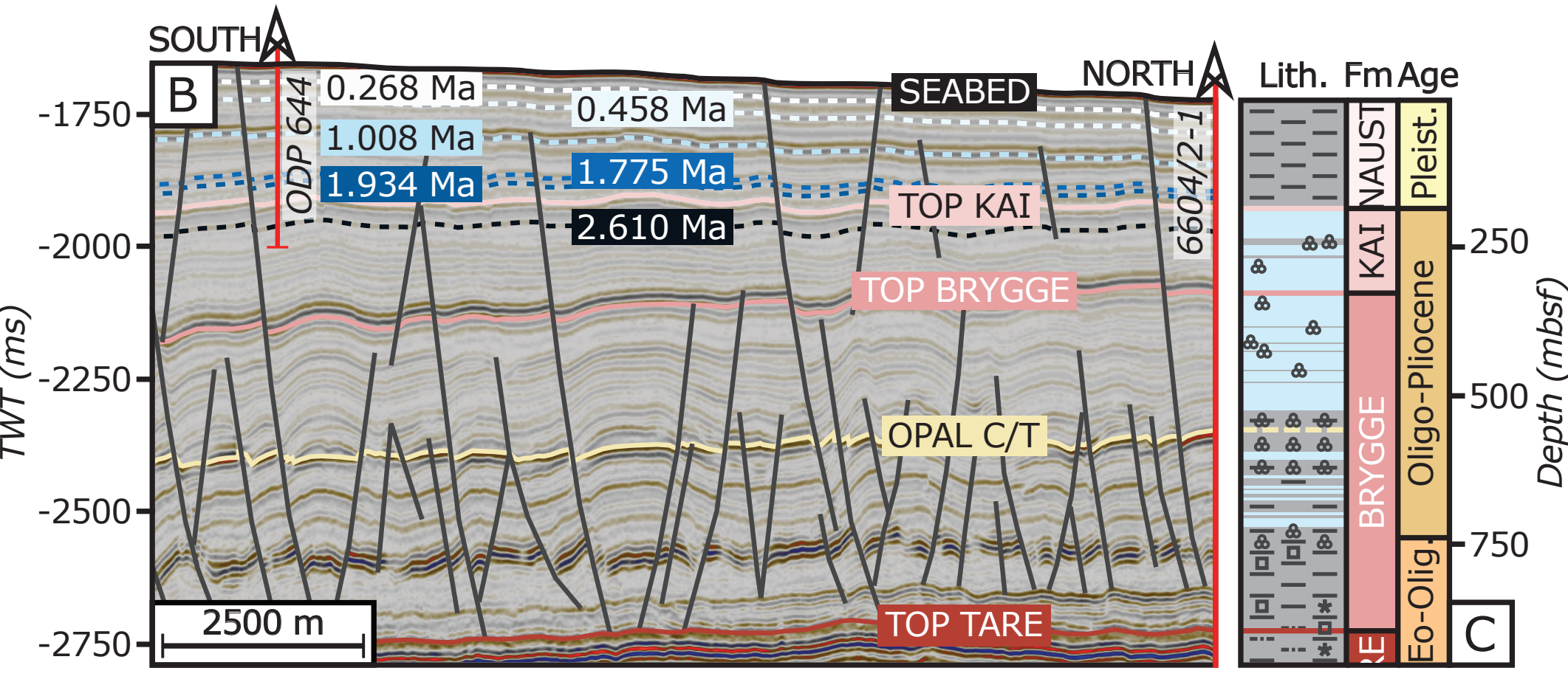



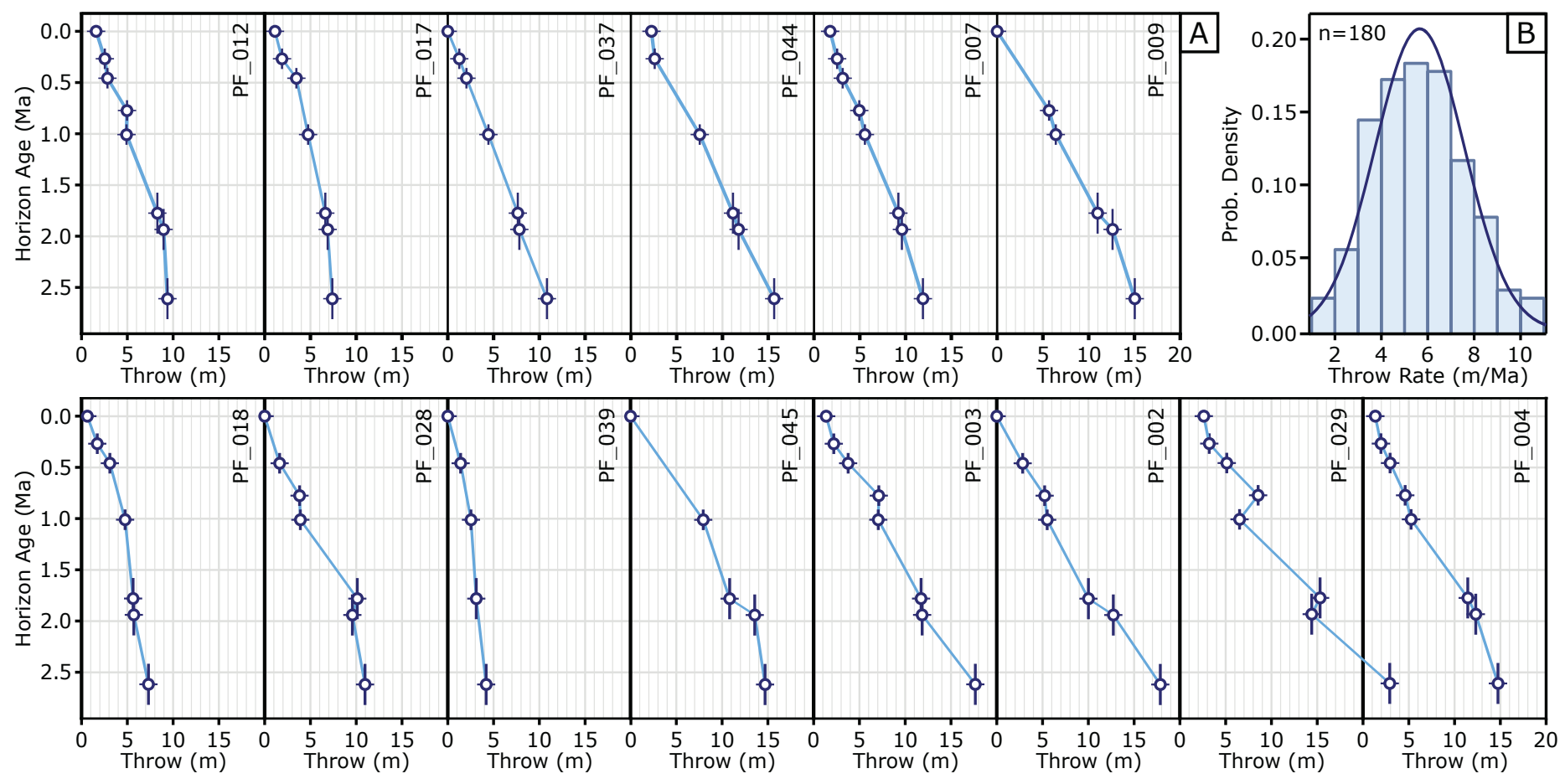
Figure 4

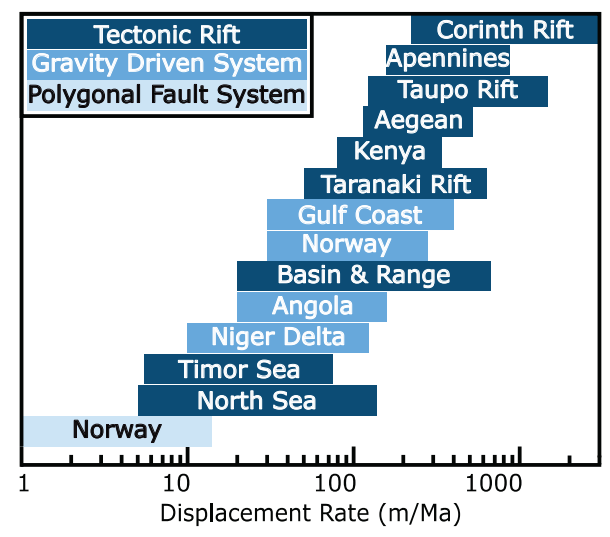

